\title{
Management of Severely Traumatized Eyes Presenting with No-Light-Perception Vision
}

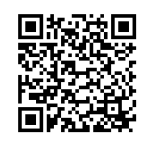

\author{
Sengul 0zdek* and Ece Ozdemir \\ Gazi University, Turkey
}

Submission: February 14, 2017; Published: March 02, 2017

*Corresponding author: Sengul Ozdek, Professor of Ophthalmology, Department of Ophthalmology, Gazi University, School of Medicine, Besevler, Ankara, 06500, Turkey, Tel: +90-530-9662142; Fax: +90-312-2857446; Email: sozdek@gazi.edu.tr/sengulozdek@gmail.com

\section{Mini Review}

Presenting visual acuity (VA) has been demonstrated to be the most reliable predictor of the functional outcome in open globe injuries [1-3]. Eyes with no-light-perception (NLP) post-injury are generally related to poor functional outcomes [4]. Traditionally, primary enucleation had been advocated for severely traumatized eyes with NLP in view of the risk of sympathetic ophthalmia [5,6]. Nevertheless, modern immunosuppressives improved the control and treatment of sympathetic ophthalmia and the reported rates of sympathetic ophthalmia is as low as $0.3 \%$ in recent studies [7]. In addition, NLP at the acute setting does not necessarily mean that this is irreversible. In the literature, visual recovery rates from NLP to LP or better vary from $4 \%$ to $33 \%[4,8-11]$.
First of all, visual acuity examination in emergency circumstances is not always reliable because the cognitive status of the patient (e.g., unconsciousness, anxiety) may easily influence the result, especially if the examiner is inexperienced. Moreover, most importantly, visual acuity may be profoundly impaired to the extent of NLP due to treatable pathologies (e.g., severe corneal edema, hyphema, dense vitreous and subretinal hemorrhage, particularly in the presence of retinal detachment, extensive choroidal hemorrhage), correction of which may reverse NLP status (Figure 1). Hence, after ascertaining the vision is NLP, clinician must try to identify if the underlying cause is reversible or irreversible. In eyes with severe media opacity, B-scan ultrasonography often aids in diagnosis.

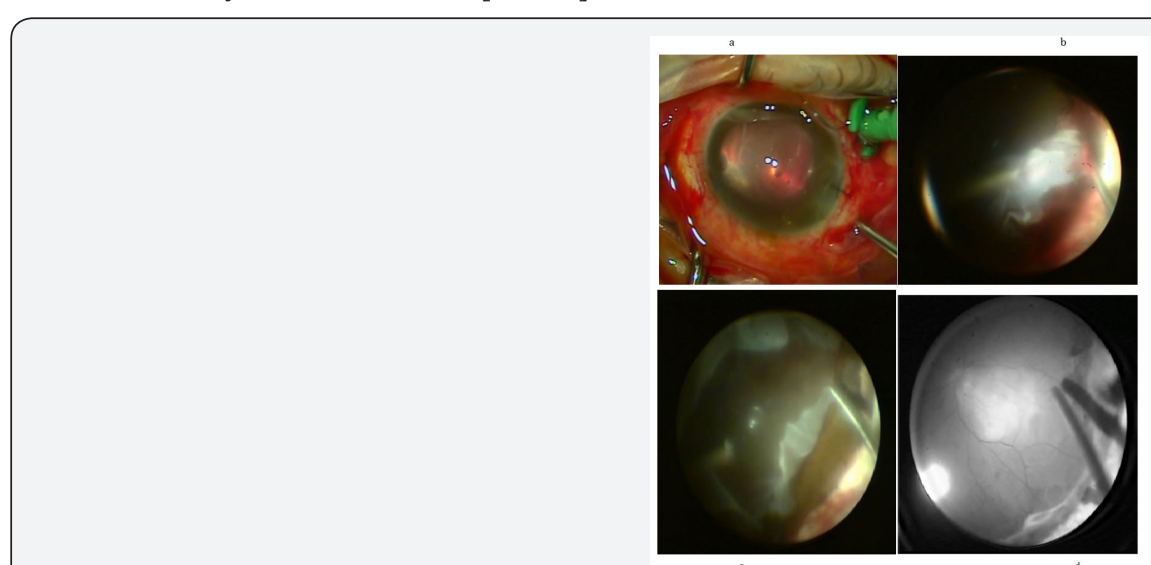

Figure 1: A case of reversible NLP status. 58 year-old female with a previous Laceration at the superotemporal area just anterior to the equator of the globe parallel to limbus and referred to us after primary repair elsewhere. She had NLP vision and preoperative USG yielded hemorrhagic retinal detachment with dense vitreous hemorrhage. He underwent surgery 7 days after primary injury; hyphema and disrupted lens are removed and an IOL was implanted (a). There was dense vitreous hemorrhage, and there was no posterior vitreous detachment. It was difficult to reach the retina and detach the posterior hyaloid. We started to dig the dense vitreous hemorrhage from the nasal side so that if retina is accidentally damaged macular damage could be avoided. Following removal of hemorrhagic vitreous, a dense subretinal hemorrhagic clot could be seen. Retina was seen to be incarcerated in the superotemporal laceration area and there was a large subretinal clot there (b). Retina was freed from the incarcerated area and a 360 retinotomy was performed to clear all the subretinal hemorrhages. Note the white sclera is seen at the superotemporal quadrant indicating the ciliary body damage in that area (c). Vitrectomy was completed with silicone oil tamponade which resulted in retinal reattachment. Silicone oil was removed 3 months after vitrectomy (d). Although the intraocular pressure was minimally hypotonic $(8 \mathrm{mmHg})$ because of the ciliary body trauma, retina remained attached and visual acuity improved to 20/100 at 12-month follow-up. 
Only in cases of optic nerve transection or complete avulsion, the ophthalmologist may be certain that NLP status is permanent $[8,9,12,13]$ (Figure 2). Relative afferent pupillary defect (RAPD) is an indicator of optic nerve damage; however, it may be falsely positive in the presence of severe hyphema, or subretinal hemorrhage [14]. CT or MRI imaging is successful to demonstrate optic nerve damage (e.g., avulsion, transection) in most of the cases. Even in these cases with no visual potential, the aim should be the anatomic salvage of the globe. Primary enucleation may only be justified if the eye is deformed to an extent that anatomic closure of the wound is not possible.

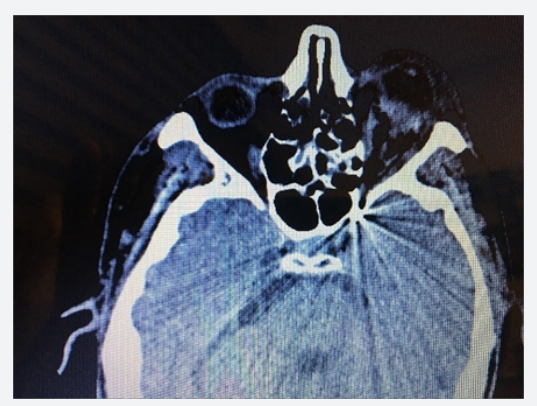

Figure 2: NLP eye with a foreign body in orbital apex. Optic nerve trauma is the cause of the lost light perception.

Secondary vitreoretinal surgery has an unquestionably critical role in preservation of vision and globe. In one study, all the eyes which had recovered from NLP without having secondary vitrectomy were observed to become phthisical with NLP vision within 7 months [10]. Another study showed that eyes that underwent secondary vitrectomy were more likely to recover from NLP vision than those that did not [13]. We advocate early secondary surgery between 3-10 days after openglobe injury. Performing vitrectomy several days after injury allows media clarity, wound stabilization and posterior vitreous detachment to set in. It also has an advantage of decreased uveal congestion which might otherwise result in uncontrollable hemorrhage [15]. However, deferring vitrectomy more than 2 weeks has severe disadvantages (proliferative vitreoretinopathy, ciliary body destruction and consequent phthisis) [16]; hence should be avoided.

Some clinical features may help to predict the visual prognosis of traumatized eyes with NLP after vitreoretinal surgery. Bhagat et al. [13] suggested that NLP eyes that had recovered LP or better vision on the first postoperative day after primary repair might be more likely to recover from NLP at the last follow-up compared to the eyes having NLP on the first postoperative day (71\% vs. $8 \%$ ) [13]. Salehi-Had et al. [10] showed that eyes which had recovered LP or better vision within 5 days of primary repair and/or had vitreoretinal surgery within 5 weeks of the initial injury achieved a more favorable visual outcome [10]. Ciliary body damage, closed funnel retinal detachment, or choroidal damage, on the other hand, has found to be risk factors for developing NLP post trauma [12]. Presence of RAPD and zone 3 wound extending beyond rectus insertion are other clinical features that have been shown to be associated with poor visual prognosis [8]. However, it should be kept in mind that these clinical findings do not necessarily indicate a definite NLP status. Awareness of visual prognosis prior to surgery is important in appropriate management strategy as well as patient counseling.

Given the low risk of sympathetic ophthalmia and advances in vitreoretinal surgical techniques, we recommend globe salvaging procedures for severely traumatized NLP eyes, unless the anatomic reconstruction is impossible. Appropriate primary repair and timely vitreoretinal intervention may give a chance for visual recovery. Even in cases with permanent visual loss, anatomic preservation of the globe should be the primary purpose as the idea of losing an eye is a devastating situation to the patient and the family. Secondary enucleation may be carried out for blind painful cosmetically unacceptable eyes or at the patient's request.

\section{References}

1. Groessl S, Nanda SK, Mieler WF (1993) Assault-related penetrating ocular injury. American journal of ophthalmology 116(1): 26-33.

2. Sternberg P, De Juan E, Michels RG, Auer C (1984) Multivariate analysis of prognostic factors in penetrating ocular injuries. Am J Ophthalmol 98(4): 467-472.

3. Williams DF, Mieler WF, Abrams GW, Lewis H (1988) Results and prognostic factors in penetrating ocular injuries with retained intraocular foreign bodies. Ophthalmology 95(7): 911-916.

4. Schmidt GW, Broman AT, Hindman HB, Grant MP (2008) Vision survival after open globe injury predicted by classification and regression tree analysis. Ophthalmology 115(1): 202-209.

5. du Toit N, Motala MI, Richards J, Murray AD, Maitra S (2008) The risk of sympathetic ophthalmia following evisceration for penetrating eye injuries at Groote Schuur Hospital. Br J Ophthalmol 92(1): 61-63.

6. Moshfeghi DM, Moshfeghi AA, Finger PT (2000) Enucleation. Surv Ophthalmol 44(4): 277-301.

7. Savar A, Andreoli MT, Kloek CE, Andreoli CM (2009) Enucleation for open globe injury. Am J Ophthalmol 147(4): 595-600.

8. Agrawal R, Wei HS, Teoh S (2012) Predictive factors for final outcome of severely traumatized eyes with no light perception. BMC Ophthalmol 12:16.

9. Soni NG, Bauza AM, Son JH, Langer PD, Zarbin MA, et al. (2013) Open globe ocular trauma: functional outcome of eyes with no light perception at initial presentation. Retina 33(2): 380-386.

10. Salehi-Had H, Andreoli CM, Andreoli MT, Kloek CE, Mukai S (2009) Visual outcomes of vitreoretinal surgery in eyes with severe openglobe injury presenting with no-light-perception vision. Graefes Arch Clin Exp Ophthalmol 247(4): 477-483.

11. Weichel ED, Colyer MH, Ludlow SE, Bower KS, Eiseman AS (2008) Combat ocular trauma visual outcomes during operations iraqi and enduring freedom. Ophthalmology 115(12): 2235-2245.

12. Feng K, Shen L, Pang X, Jiang Y, Nie H, et al. (2011) Case-control study of risk factors for no light perception after open-globe injury: eye injury vitrectomy study. Retina 31(10): 1988-1996. 
13. Bhagat N, Turbin R, Langer P, Soni NG, Bauza AM, et al. (2016) Approach to Management of Eyes with no Light Perception after Open Globe Injury. J Ophthalmic Vis Res 11(3): 313-318.

14. Striph GG, Halperin LS, Stevens JL, Chu FC (1988) Afferent pupillary defect caused by hyphema. Am J Ophthalmol 106(3): 352-353.

15. Mittra RA, Mieler WF (1999) Controversies in the management of open-globe injuries involving the posterior segment. Surv Ophthalmol 44(3): 215-225.

16. Cleary PE, Ryan SJ (1981) Vitrectomy in penetrating eye injury. Results of a controlled trial of vitrectomy in an experimental posterior penetrating eye injury in the rhesus monkey. Arch Ophthalmol 99(2): 287-292.

\section{Your next submission with Juniper Publishers} will reach you the below assets

- Quality Editorial service

- Swift Peer Review

- Reprints availability

- E-prints Service

- Manuscript Podcast for convenient understanding

- Global attainment for your research

- Manuscript accessibility in different formats

( Pdf, E-pub, Full Text, Audio)

- Unceasing customer service

Track the below URL for one-step submission https://juniperpublishers.com/online-submission.php 